ISSN 2564-016X

OPEN 2 ACCESS Freely available online

M - 00206 | Inaugural Editorial

\title{
ENVIRONMENTAL JUSTICE AND INCLUSIONS Inaugural Editorial
}

\author{
Kamrul Hossain \\ (Editor-in-Chief, Journal of Environmental Law \& Policy) \\ Northern Institute of Minority and Environmental Law, \\ The Arctic Centre, University of Lapland, Rovaniemi, Finland \\ Email: kamrul.hossain@ulapland.fi
}

The environmental agenda encompasses a relatively large number of issues having multiple actors involved in and around them. Environmental problems are diverse and complex, both in local as well as in international settings. The complexity of environmental problems often involves exploring various solution approaches. The regulatory process is one of them; and the policy process complements regulatory developments. They guide human behaviour. Given that human interactions with nature and ecological processes are central to environmental problems, law and policy regulations suggest changing human behaviour in order to be in harmony with nature and to better cope with natural processes. Coping with natural processes does not mean seeking the adoption of preventive measures only. Rather, positive and proactive measures are necessary to recover from environmental harm, as we have already caused significant damage to our environment. We must recover from the injury caused to our planet in order for it to exist in its unique condition and to continue with life support systems that are sustainable. Law and policies are some of the tools we employ to recover from the damages caused to our environment. Since the 1972 Stockholm Conference on the Human Environment, the environmental agenda has predominantly captured our attention on all decision-shaping and decision-making levels, including political, economic, scientific, and cultural spheres both in academic and non-academic contexts. The actors' joint efforts have provided us with a mutual understanding of environmental problems, a set of agreed-upon norms and principles, and procedural practices to respond to such problems.

How to cite this paper: Kamrul Hossain, 'Environmental Justice and Inclusions' (2021) 001 Journal of Environmental Law and Policy 1-5. <https://doi.org/10.33002/jelp001.00>

Copyright (C) 2021 by author(s). This work is licensed under the Creative Commons Attribution International License (CC BY 4.0). http://creativecommons.org/licenses/by/4.0/

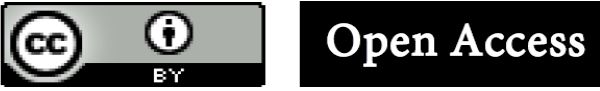


However, in the international context, the state-centric legal framework adopts a consent-based approach. The legal norms and rules are binding for states only when these norms and rules are emanating from states' free will, as expressed either in treaties and conventions or by usages generally accepted as part of the customary international norms. States tend to balance their free will with their national interests while committing to environmental regulations. Therefore, even though there is a shared understanding of environmental problems, their solutions are not always likely to be achieved through strict legal mechanisms-nor is it an ideal approach to solve environmental problems by stringent regulatory tools only. Environmental problems are interconnected and dynamic; they constantly transform due to both natural processes and the human interactions with such processes. Environmental problems know no borders. Hence, the environmental impacts transcend the territories where the problems originated. The impacts are also dynamic; they affect different regions differently. They demand differentiated responses following differentiated impacts. Environmental problems are not merely inter-state matters; they are often global problems - calling for an alternative to the traditional governance approach with just state actors - and, thus, require bringing all relevant actors, such as non-state actors, local sub-national actors, and all sorts of stakeholders, together. Such a governance approach calls for a meeting point within top-down and bottom-up structures, making environmental law and policy more representative, democratic, and legitimate.

We strive to adopt such a unique, global approach to environmental governance in order to deal with climate change, biodiversity conservation, natural resource management, etc. Sharing responsibilities in our performances, which are guided by the norms and principles developed to date, is the core of environmental management. Such a process requires us to take actions toward ensuring overall environmental justice and the promotion of inclusions. Both environmental justice and inclusions are mutually reinforcing - environmental justice demands broader inclusions in the governance approach, and, at the same time, inclusions promote environmental justice.

The phrase "environmental justice" must not be understood merely in the climate change context concerning the divides between the global south and the global north. Indeed, territoriality is an essential component, for example, for measuring the emission range of greenhouse gases, identifying the nations that have the highest emissions, and recognizing the nations that suffer from the adverse consequences despite their innocence. Territoriality is crucial to sharing the responsibilities and burdens associated with climate change mitigation processes among different nations. Climate change is often considered to be a threat multiplier because of its widespread consequences in all aspects of life, including the environmental, socioeconomic, political, and cultural contexts. These widespread consequences deepen the challenges to both the environment and society at large, leading 
to a threat to human security and development and resulting in an exacerbation of inequality and social injustice.

The understanding of environmental justice goes beyond territoriality regimes and involves people and communities within the specific territorial regime, but also across territories. For example, local and Indigenous communities are vulnerable to the effects of global climate change. Often, these groups rely on having a pristine natural environment for their traditional livelihoods and subsistence, which, particularly for Indigenous peoples, are nature-based activities in most cases. Such practices offer them a unique cultural and ethnic identity as distinct groups of people. While these groups live in harmony with nature and do not cause harm to the natural environment themselves, they, however, share the burden arising out of environmental changes caused by actors from within and beyond their territories. In most cases, Indigenous peoples and other local communities face a disproportionate amount of the environmental degradation to which they do not contribute themselves. Quite contrarily, they serve the stewardship role in the environmental conservation process, via environmental management and development through their unique knowledge. Principle 22 of the Rio Declaration on Environment and Development of 1992 recognized their knowledge and the vital role it plays in environmental management. Today, international regulatory tools increasingly stipulate provisions acknowledging their role in environmental governance. The Convention on Biological Diversity (CBD) of 1992, and its subsequent Protocols, the Convention on Wetlands of International Importance or the Ramsar Convention of 1971, and the most recent Paris Agreement of 2015 within the framework of climate change regime, are some of the environmental treaties that explicitly refer to Indigenous peoples and local communities and their importance for inclusions in environmental lawmaking processes.

The process of inclusion of Indigenous and local communities within the climate change regime shows a unique example. The Indigenous peoples' representation is carried out by the International Indigenous Peoples' Forum on Climate Change (IIPFCC), established in 2008 as the Caucus for Indigenous Peoples. During the adoption of the Paris Agreement, the IIPFCC presented proposals for their inclusion in the process, which resulted in the recognition of Indigenous peoples and local communities. The Preamble and Article 7 of the Paris Agreement referred to Indigenous and local communities and noted the importance of their traditional knowledge and local knowledge systems on the adaptation to integrate them into the relevant socio-economic and environmental policies and actions, where appropriate. The Local Communities and Indigenous Peoples Platform (LCIP Platform) was established as a non-party stakeholder to enhance their participatory role. The implementation of enhanced inclusion has been discussed in the subsequent Conferences of the Parties (the CoPs). For example, in 2018, CoP 24 (held in Katowice) adopted a decision (2/CP.24) to establish the LCIP Platform Facilitative Working Group (FWG) to further 
operationalize the LCIP Platform and facilitate the implementation of its functions. The most important aspect in this decision was choosing and appointing local and Indigenous peoples as representatives by themselves and on equal terms along with the state party representatives.

Additionally, the inclusion of Indigenous peoples in environmental matters is also reflected in processes undertaken within the United Nations' structure, such as the United Nations Environmental Program (UNEP). In 2004, the UNEP established the Focal Point on Indigenous Issues, who is a liaison officer that communicates with Indigenous representatives and ensures their participation in the UNEP processes in environmental governance. The UNEP accredits Indigenous organisations for participating in, for example, the United Nations Environmental Assembly (UNEA) - the United Nations' highest-level decision-making body on environmental issues. The UNEA was established in the Rio+20 conference in 2012 and calls for global action to address the critical environmental challenges facing the world.

Today, human rights norms link environmental justice both as a substantive right and a procedural right. Although the mainstream human rights treaties, such as the International Covenant on Civil and Political Rights (ICCPR) and the International Covenant on Economic, Social and Cultural Rights (ICESCR), have not explicitly referred to a right to the environment, today, a human rights-based approach to environmental governance has become the norm. In 1993, the World Conference on Human Rights held in Vienna adopted the Vienna Declaration and Programme of Action (VDPA), which articulated a right to development based on equitable grounds by meeting environmental needs for both present and future generations. Simultaneously, the VDPA reconfirmed the protection of minorities and Indigenous peoples to profess and practice their own culture, which necessitates a harmonious environmental governance approach, as stated previously. The famous Inuit Petition of 2004 was the first step that showed a concrete case on the relationship between Indigenous peoples' human rights and climate change. The Inuit leaders from the Inuit Circumpolar Council (ICC) filed a petition to the Inter-American Commission on Human Rights (IACHR) complaining that the absence of the United States (US) in mitigating the climate change process caused human rights violations for the Inuit inhabiting the Arctic regions of the US and Canada. As the Inuit culture is heavily dependent on the presence of ice, which they use to help them hunt, gather food, communicate, etc., the loss of ice resulting from global warming heavily impacts their way of life and their cultural survival. Despite its failure to be cognized by the IACHR due to insufficient information for determining the consequence, the petition offers normative guidance establishing a link between climate change and human rights. Climate change, as one of the main driving forces for environmental change, results in land degradation, coastal erosion, loss of ice, and an increase in natural disasters, among other things, which bring about significant adverse consequences to enjoying many basic human 


\section{Environmental Justice and Inclusions}

rights. For example, climate change has caused both an internal and external displacement of populations, making individuals become environmental refugees, and leading to political and social problems, both in national and international contexts, which has resulted in diverse forms of inequality and injustice. Broadly, therefore, a lack of the right to a sound environment causes a violation of substantial human rights components, such as the right to life. The United Nations Human Rights Council, in its most recent session (the $46^{\text {th }}$ Session) held on 22 February-19 March 2021, adopted a resolution on human rights and the environment that explicitly confirms that the enjoyment of human rights is integrally linked to a healthy environment.

The points stated herein are only a very small fraction of the environmental challenges that exist today. There have been significant efforts undertaken to meet these challenges and promote inclusion and justice within our environmental governance approaches. Yet, there are significant demands ahead of us to promote knowledge and to better understand both global and local environmental problems and their solutions. This newly established journal, the Journal of Environmental Law \& Policy, joins the effort for knowledge promotion by debating various environmental governance approaches and utilizing an interdisciplinary perspective with a broad focus. This journal intends to join the global movement for attaining the sustainable development goals set by the United Nations in the exchange of knowledge and information on both legal and policy perspectives, from both national and international environmental law and policy contexts. 